\title{
Kuromoji (Lindera umbellata) essential oil-induced apoptosis and differentiation in human leukemia HL-60 cells
}

\author{
HAYATO MAEDA, MAO YAMAZAKI and YOHTARO KATAGATA \\ Faculty of Agriculture and Life Science, Hirosaki University, Hirosaki, Aomori 036-8561, Japan
}

Received July 8, 2011; Accepted August 1, 2011

DOI: 10.3892/etm.2011.357

\begin{abstract}
Essential oils diluted from certain plants have been shown to have antitumor activity against several human tumor cell lines. Kuromoji (Lindera umbellata) essential oil (KEO) has long been used in Japan as a traditional medicine. KEO and its major chemical constituent, linalool, were investigated in this study for their ability to induce apoptosis and differentiation in human leukemia HL-60 cells. HL-60 cells were treated with 5 or $50 \mu \mathrm{g} / \mathrm{ml} \mathrm{KEO}$ or linalool for 24 or $48 \mathrm{~h}$. Then, cell proliferation and apoptosis induction were estimated. In addition, HL-60 cells are known to differentiate into granulocyte or monocytes by a variety of compounds. Therefore, the effect of KEO or linalool on differentiation of HL-60 cells was assessed by Giemsa stain and a nitroblue tetrazolium reduction assay. Cells treated with KEO or linalool for 48 h showed significantly suppressed cell proliferation, with induced apoptosis. Moreover, KEO and linalool promoted cell differentiation. Treatment with KEO cells at the same dose as linalool showed an almost identical effect on HL-60 cells. These results suggest that KEO and linalool have efficacy as anticancer therapeutic products.
\end{abstract}

\section{Introduction}

Second to cardiovascular disease, cancer is the leading cause of death throughout the world. Cancer cells evade self-demise through apoptosis by the accumulation of several genetic and epigenetic changes (1). Therefore, agents that trigger apoptosis in cancer cells are regarded as important for the development of anticancer chemotherapeutics (2). In addition, cancer cells, including leukemia cells, exhibit a defect in their capacity to mature to non-replicating adult cells, therefore remaining in a highly proliferative state and outgrowing their normal cellular counterparts $(3,4)$. Induction of terminal differentiation, leading to the eventual elimination of tumorigenic cells and

Correspondence to: Dr Hayato Maeda, Faculty of Agriculture and Life Science, Hirosaki University, 3 Bunkyo-cho, Hirosaki, Aomori 036-8561, Japan

E-mail: hayatosp@cc.hirosaki-u.ac.jp

Key words: essential oil, Kuromoji, Lindera umbellata, leukemia, linalool, HL-60 cells reestablishment of normal cellular homeostasis, represents an alternative approach to cancer treatment using conventional antitumor agents.

Essential oils diluted from several plants have been used for a long time in perfumery, aromatherapy, food and flavors. Many essential oils are known to be potent antibacterial and antifungal agents. Certain essential oil components have been reported to have anticancer activity (5). The advantage of these components in anticancer therapy is their low or negligible toxicity. Therefore, such components can be used for the long-term treatment of chemoprevention and chemotherapy of cancer (6).

Kuromoji (Lindera umbellata) is a deciduous shrubby tree that is native to cool or warm temperate areas of Japan. It is known as a spicebush because it contains aromatic components in its twigs and leaves. Consequently, Kuromoji branches have been used for indoor decorations and to produce shavings for aromatic baths. Furthermore, Kuromoji essential oil (KEO) obtained through steam distillation has been used traditionally as a medicine for neuralgia, stiff neck and back pain. The main KEO components are terpenes and alcohol esters; linalool is the most abundant component. Geranyl acetate, an ester contained in KEO contributes a relaxing and calming effect on humans. Other terpenes (limonene and $\alpha$-pinene) and alcohols (geraniol and cineol) in essential oil have beneficial activities for various diseases, supporting anti-inflammatory and anti-obesity effects.

Linalool reportedly possesses strong activity against U937 histiocytic lymphoma cells and P3HR1 Burkitt lymphoma cells (7). Moreover, several recent reports have revealed that linalool reverses doxorubicin resistance in human breast adenocarcinoma cells (8) and exhibits antiproliferative activity against certain solid tumor cells, such as melanoma and renal cell adenocarcinoma cells (9), and HepG2 (10). Particularly, linalool induces apoptosis in human leukemia cells without affecting normal hematopoietic cell growth (11). These terpenoid components become ligands in nuclear receptors, regulate expression of various genes and ameliorate conditions related to these diseases (12).

Human myeloid leukemia cells, specifically HL-60 cells, are known to differentiate into granulocytes or monocytes when treated with a variety of compounds, such as all-transretinoic acid (ATRA), dimethyl sulfoxide and vitamin D3 $(13,14)$. In particular, ATRA is a class of chemical compounds that are structurally related to vitamin A; ATRA is one class 
of compounds known as retinoids, which are used for clinical therapy for acute promyelocytic leukemia (APL) (13). These retinoid components become ligands of nuclear receptors; they regulate cell proliferation and differentiation (15).

This study was undertaken to investigate whether KEO induces apoptosis and promotes differentiation in human leukemia HL-60 cells. The results suggest that KEO may be available for use as a natural therapeutic agent of APL.

\section{Materials and methods}

Chemical reagents and cells. For use in this study, HL-60 cells (ATCC CCL240) were obtained from DS Pharma Biomedical Co., Ltd. (Osaka, Japan). Fetal bovine serum (FBS) was purchased from Biological Industries Ltd. (Kibbutz, Beit, Israel). RPMI-1640 medium was purchased from Sigma-Aldrich Japan (Tokyo, Japan). ATRA was purchased from Wako Pure Chemical Industries, Ltd. (Osaka, Japan). A sandwich ELISA kit used to estimate the levels of histone-associated DNA fragments was purchased from Roche Diagnostics GmbH (Mannheim, Germany). All other chemicals, guaranteed to be of reagent or tissue-culture grade, were obtained from Sigma-Aldrich Japan or Wako Pure Chemical Industries, Ltd.

Isolation of Kuromoji essential oil. KEO was donated from Senjyakudo (Aomori, Japan). Fresh Kuromoji leaves and branches were collected in the mountains near Aomori city. These ingredients were heated to boiling temperature. The hydro-distilled volatile part was subsequently collected and separated (upper layer) from the aqueous portion.

Analysis of KEO constituents was carried out using gas chromatography-MSat the AomoriPrefecturalIndustrialTechnology Research Center. The GC-MS system (GC-17A/QP-5000; Shimadzu Corp.) was equipped with a DB-1701 column (30 mm x $0.25 \mathrm{~mm} \times 0.25 \mu \mathrm{m}$; J\&W Scientific Inc.). The carrier gas was helium. The program was operated with the following oven temperature program: $50^{\circ} \mathrm{C}$, held for $5 \mathrm{~min}$, rising at $5^{\circ} \mathrm{C} / \mathrm{min}$ to $100^{\circ} \mathrm{C}$, rising at $2^{\circ} \mathrm{C} / \mathrm{min}$ to $150^{\circ} \mathrm{C}$, rising at $10^{\circ} \mathrm{C} / \mathrm{min}$ to $250^{\circ} \mathrm{C}$; the injection temperature and volume were $270^{\circ} \mathrm{C}$ and $1.0 \mu \mathrm{l}$, respectively. Constituents were identified by computer matching of mass spectral data with data from the NIST62 mass spectral database (Shimadzu Corp.). The major constituents of KEO were linalool $(65.78 \%)$, geranyl acetate $(17.59 \%)$, geraniol $(5.29 \%)$, cineol $(2.34 \%)$, limonene $(2.11 \%)$, 3 -carene $(1.78 \%), \alpha$-pinene $(1.43 \%)$ and carvone $(1.18 \%)$.

Cell culture. HL-60 cells were cultured in RPMI-1640 medium supplemented with $10 \%$ heat-inactivated FBS, $100 \mu \mathrm{g} / \mathrm{ml}$ streptomycin and $100 \mathrm{IU} / \mathrm{ml}$ penicillin at $37^{\circ} \mathrm{C}$ in a $5 \% \mathrm{CO}_{2}$ humidified incubator. For each experiment, HL-60 cells were seeded at a density of $5 \times 10^{4}$ cells $/ \mathrm{ml}$. As an ethanol solution, KEO, ATRA and linalool were added to the culture medium. The final concentration of ethanol was $<0.1 \%(\mathrm{v} / \mathrm{v})$.

Proliferation of HL-60 cells. HL-60 cells $\left(5 \times 10^{4}\right.$ cells $\left./ \mathrm{ml}\right)$ were incubated in the culture medium containing KEO, ATRA or linalool. The cell number was determined using a hematocytometer, and cell viability was determined with a dye exclusion test using trypan blue.
ELISA analysis. DNA fragmentation was estimated using a biotin-labeled anti-histone antibody and a peroxidaseconjugated anti-DNA-antibody in a sandwich ELISA kit. First, HL-60 cells $\left(5 \times 10^{4}\right.$ cells $\left./ \mathrm{ml}\right)$ were treated with KEO or linalool. Then, cells were washed with PBS and lysed with $200 \mu 1$ or lysis buffer for $30 \mathrm{~min}$ at room temperature. The lysate was centrifuged at $200 \mathrm{x} \mathrm{g}$ for $10 \mathrm{~min}$, and $20 \mu \mathrm{l}$ of supernatant was transferred onto a streptavidin-coated microtiter plate. The presence of histone-associated DNA fragments in the cell lysates was determined using a sandwich ELISA kit. The level of DNA fragmentation of mononucleosomes and oligonucleosomes in HL-60 cells was expressed as an enrichment factor, as calculated using the following formula: Enrichment factor $=\mathrm{mU}$ of the sample (HL-60 cells treated with sample)/ $\mathrm{mU}$ of the corresponding control (HL-60 cells without sample treatment); $\mathrm{mU}=$ absorbance $\left(\mathrm{A}_{405 \mathrm{~nm}}\right)$.

Staining and nitroblue tetrazolium reduction assay. As an indicator of HL-60 cell differentiation, a nitroblue tetrazolium (NBT) reduction assay was utilized (16). After HL-60 cells were treated with the samples for $72 \mathrm{~h}$, they were suspended in PBS; Giemsa stain results were then observed using microscopy (x400). Subsequently, the cell pellet was centrifuged at $500 \mathrm{x} \mathrm{g}$ for $5 \mathrm{~min}$ and rinsed three times with PBS. The cells were suspended in $0.5 \mathrm{ml}$ of NBT solution containing $2 \mathrm{mg} / \mathrm{ml}$ of NBT and $200 \mathrm{ng} / \mathrm{ml}$ TPA in PBS. They were then incubated for $30 \mathrm{~min}$ at $37^{\circ} \mathrm{C}$. The cells were washed with aliquots of PBS and resuspended in $0.1 \mathrm{ml}$ of PBS. HL-60 cells do not produce superoxide anions $\left(\mathrm{O}^{2-}\right)$, but when they differentiate, they start to produce $\mathrm{O}^{2-}$. They then form blue-black formazan deposits by reducing the NBT reagent. For each determination, at least 200 cells were counted using a hematocytometer. The number of NBT-positive cells containing intracellular formazan deposits was expressed as a percentage of the viable cell number.

Statistical analysis. The results are expressed as the means \pm standard deviation (SD). Statistical analyses between multiple groups were performed using ANOVA.

Statistical comparisons were carried out using Dunnet's multiple comparison test. Differences were considered significant at $\mathrm{p}<0.05$ or $\mathrm{p}<0.01$. Analyses were performed using StatView-J software ver. 5.0 (Abacus Concepts, Inc., Berkeley, CA, USA).

\section{Results}

Kuromoji essential oil inhibits cell proliferation. The effect of KEO on the growth of HL-60 cells was examined (Fig. 1). The HL-60 cells were treated with 5 or $50 \mu \mathrm{g} / \mathrm{ml} \mathrm{KEO}$ or linalool for 24 or $48 \mathrm{~h}$, and cell proliferation was assessed using a dye exclusion test using trypan blue. The number of viable cells treated with linalool at $50 \mu \mathrm{g} / \mathrm{ml}$ for $24 \mathrm{~h}$ was significantly $(\mathrm{p}<0.05)$ suppressed compared to the control cells. After $48 \mathrm{~h}$ of treatment with KEO or linalool, the cell growth was inhibited significantly in a dose-dependent manner.

Fig. 2 presents an illustration of the apoptosis-inducing activity in the HL-60 cells treated with KEO or linalool for $48 \mathrm{~h}$. Enrichment of mononucleosomes and oligonucleosomes in the HL-60 cells was estimated using sandwich ELISA after 


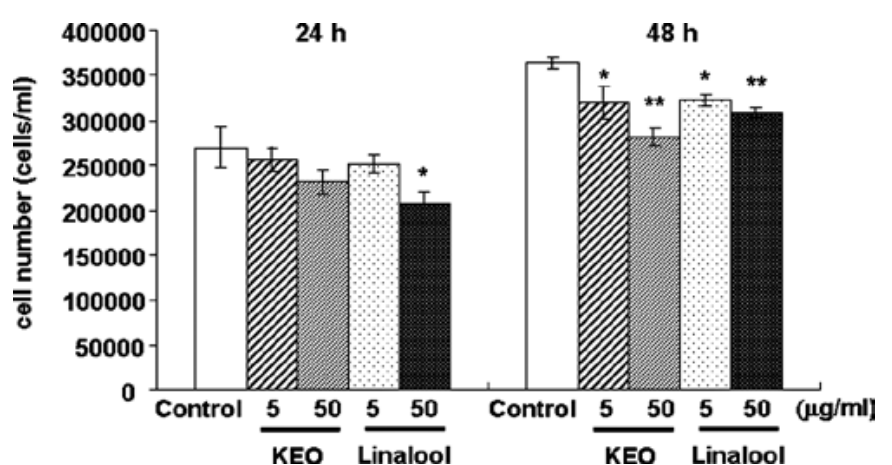

Figure 1. Effects of KEO or linalool on the viability of HL-60 cells. HL-60 cells $\left(5 \times 10^{4}\right.$ cells $\left./ \mathrm{ml}\right)$ were incubated with KEO or linalool at 5 or $50 \mu \mathrm{g} / \mathrm{ml}$ for 24 or 48 h. ${ }^{*} p<0.05$ vs. control; ${ }^{* *}$ p $<0.01$ vs. control.

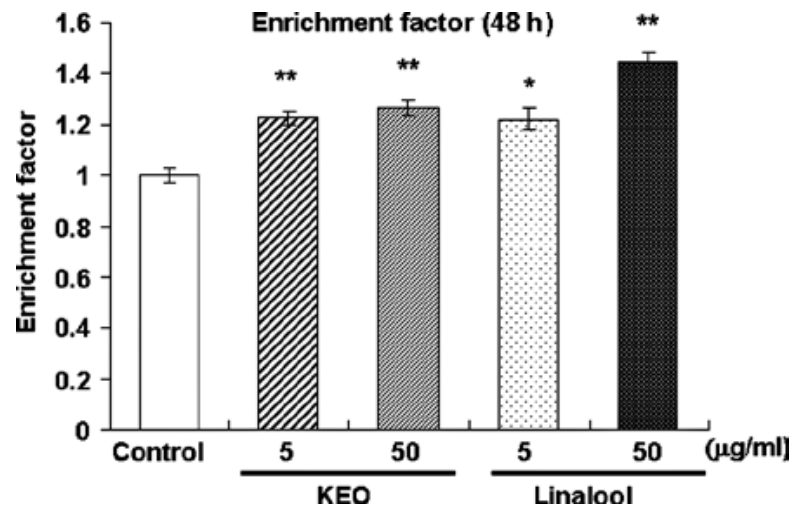

Figure 2. Effects of KEO or linalool on DNA fragmentation in HL-60 cells $\left(5 \times 10^{4}\right.$ cells $\left./ \mathrm{ml}\right)$ incubated with KEO or linalool for $48 \mathrm{~h}$. DNA fragmentation was analyzed using sandwich ELISA with the biotin-labeled anti-histone antibody and peroxidase-conjugated anti-DNA antibody. The level of DNA fragmentation was expressed as an enrichment factor relative to the untreated cells (control). ${ }^{*} \mathrm{p}<0.05$ vs. control; ${ }^{* *} \mathrm{p}<0.01$ vs. control.

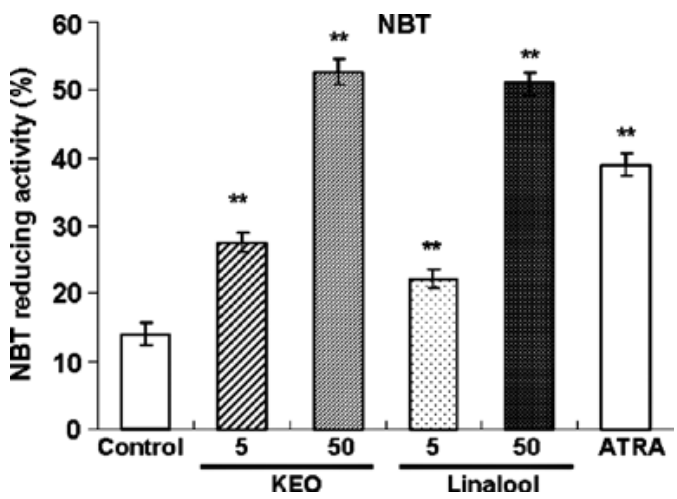

Figure 3. Effect of KEO or linalool on NBT reduction in HL-60 cells HL-60 cells were cultured with KEO or linalool at 5 and $50 \mu \mathrm{g} / \mathrm{ml}$, or ATRA at $1 \mu \mathrm{M}$ for $72 \mathrm{~h}$, and the NBT reducing activity was determined. ${ }^{* *} \mathrm{p}<0.01$ vs. control.

treatment with KEO or linalool for $48 \mathrm{~h}$. The fragmented DNA content, designated as an enrichment factor, increased $(\mathrm{p}<0.05$ or $\mathrm{p}<0.01)$ in the HL-60 cells treated with KEO and linalool compared to the control cells. These results suggest that KEO and linalool suppress HL-60 cell proliferation by inducing apoptosis.
A

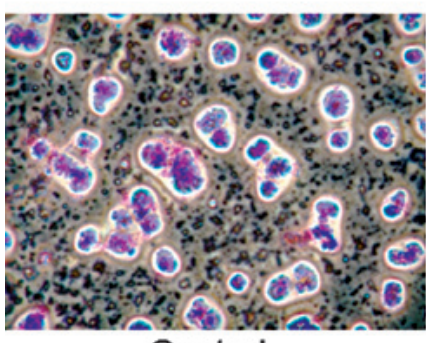

Control

C

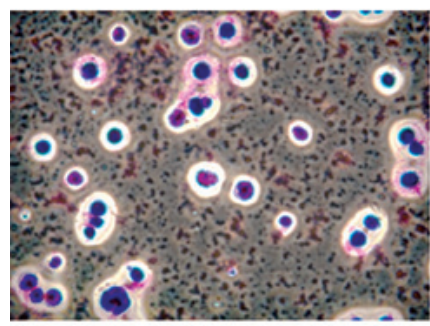

Linalool $5 \mu \mathrm{g} / \mathrm{ml}$
B

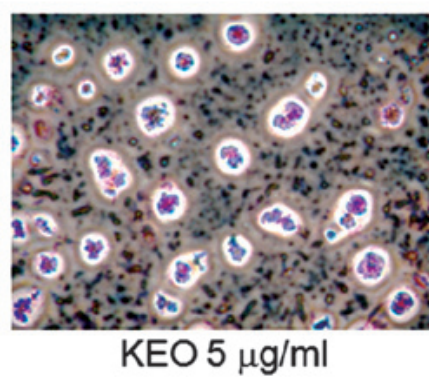

D

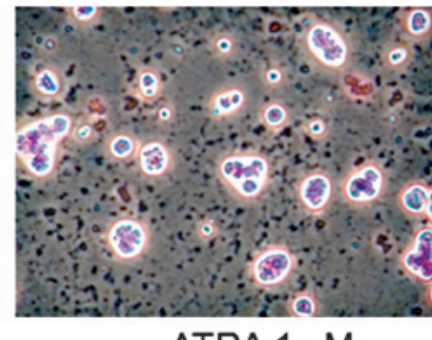

ATRA $1 \mu \mathrm{M}$

Figure 4. Effect of KEO on morphological changes in HL-60 cells.

Effect of KEO or linalool on the differentiation of HL-60 cells. Treatment with KEO or linalool enhanced the NBT-reducing activity in the HL-60 cells (Fig. 3). Treatment with $1 \mu \mathrm{M}$ ATRA increased the NBT-reducing activity. Treatment of the HL-60 cells with KEO at 5 and $50 \mu \mathrm{g} / \mathrm{ml}$ promoted the NBT-reducing activity in a dose-dependent manner. Effects of KEO and linalool treatment on the HL-60 cells were almost equal for equivalent concentrations.

Furthermore, the morphology of cells treated with KEO was observed using the Giemsa staining method (Fig. 4). Control cells were round and the ratio of the nucleus to cytoplasm was high (Fig. 4A). By contrast, irregular and small nuclei, which are typical shapes of differentiation-induced cells, were observed in cells treated with KEO $(5 \mu \mathrm{g} / \mathrm{ml})$, linalool $(5 \mu \mathrm{g} / \mathrm{ml})$ or ATRA (1 $\mu \mathrm{M})$ (Fig. 4B-D).

\section{Discussion}

This study demonstrated that KEO and its major chemical constituent linalool exhibit anticancer therapeutic effects in HL-60 cells. Treatment with 5 or $50 \mu \mathrm{g} / \mathrm{ml} \mathrm{KEO} \mathrm{suppressed}$ the growth of HL-60 cells after $48 \mathrm{~h}$. Treatment with linalool cells at the same dose of KEO showed an almost identical effect on HL-60 cells. Cell proliferation is a key to the promotion and progression of carcinogenesis. Therefore, we investigated the apoptosis-inducing activity of KEO and linalool. The fragmented DNA content increased in cells treated with KEO and linalool for $48 \mathrm{~h}$. This result suggests that KEO has leukemia cell apoptosis-inducing activity. Gu et al observed that linalool arrested growth arrest and caused apoptosis of various human leukemia cells, but noted that it spared normal hematopoietic cells (11). Linalool is the predominant component of KEO $(65.78 \%)$. Therefore, it was presumed that linalool was the most active component of KEO in inducing apoptosis of HL-60 cells. Reportedly, cineole, another KEO component, was also 
found to exhibit a suppressive effect on leukemia cell lines resulting from the induction of apoptosis (17). Consequently, co-efficiency of these components has been considered. Thus, further studies are necessary to clarify the active component.

The present study demonstrated that KEO exhibits apoptotic effects in HL-60 cells. However, the effect was not strong when compared to effects reported in a previous study (11). Reportedly, many natural compounds enhance the effects of leukemia cell differentiation (18). Treatment with KEO increased the differentiation of mature cells, similar to that noted in ATRA-treated cells. Nuclear receptors are known to mediate the actions of ATRA on cell differentiation (19). Nuclear receptor families of retinoic acid receptors (RARs) and retinoid $\mathrm{X}$ receptors (RXRs) are associated with the differentiation transcription of various genes related to the differentiation of HL-60 cells. Actually, ATRA is known to induce the differentiation of HL-60 cells to granulocytes as mediated by RARs (20). Presumably, KEO and linalool regulate the expression of related differentiation genes as mediated by RARs or RXRs. Therefore, detailed mechanisms of the differentiation effects of KEO and linalool should be examined further.

ATRA was found to induce complete remission in a high percentage of patients with APL, although the response is sometimes quite slow (21). Furthermore, relapse and resistance to treatment often occur despite continued treatment with ATRA (22). Moreover, chemotherapy with ATAR infrequently induces Sweet's syndrome, which is characterized by acute onset of inflammatory skin nodules associated with systemic features which include malaise, fever and neutrophilia (23). Consequently, combination treatment strategies have been suggested to circumvent these problems.

In conclusion, results of this study revealed that $\mathrm{KEO}$ as well as its major chemical linalool induce apoptosis and differentiation in human leukemia HL-60 cells. The possibility exists that KEO and linalool, currently applied as an essential oil in aromatherapy, can be developed into an anticancer therapeutic product.

\section{Acknowledgements}

This study was supported by a grant-in-aid for Young Scientists (21780119) from the Japan Society for the Promotion of Science (JSPS) Fellows from the Ministry of Education, Culture, Sports, Science and Technology of Japan. The authors are grateful to the Aomori Prefectural Industrial Technology Research Center and Senjyakudo for preparing the KEO.

\section{References}

1. Klein G: Cancer, apoptosis, and nonimmune surveillance. Cell Death Differ 1: 13-17, 2004.

2. Lee KH: Anticancer drug design based on plant-derived natural products. J Biomed Sci 4: 236-250, 1999.

3. Pierce GB and Speers WC: Tumors as caricatures of the process of tissue renewal: prospects for therapy by directing differentiation. Cancer Res 48: 1996-2004, 1988.

4. Beere HM and Hickman JA: Differentiation: a suitable strategy for cancer chemotherapy? Anticancer Drug Des 4: 299-322, 1993.
5. Edris AE: Pharmaceutical and therapeutic potentials of essential oils and their individual volatile constituents: a review. Phytother Res 4: 308-323, 2007.

6. Kumar A, Malik F, Bhushan S, Sethi VK, Shahi AK, Kaur J, Taneja SC, Qazi GN and Singh J: An essential oil and its major constituent isointermedeol induce apoptosis by increased expression of mitochondrial cytochrome $\mathrm{c}$ and apical death receptors in human leukaemia HL-60 cells. Chem Biol Interact 3: 332-347, 2008.

7. Chiang LC, Chiang W, Chang MY, Ng LT and Lin CC: Antileukemic activity of selected natural products in Taiwan. Am J Chin Med 31: 37-46, 2003.

8. Ravizza R, Gariboldi MB, Molteni R and Monti E: Linalool, a plant-derived monoterpene alcohol, reverses doxorubicin resistance in human breast adenocarcinoma cells. Oncol Rep 20: 625-630, 2008.

9. Loizzo MR, Tundis R, Menichini F, Saab AM, Statti GA and Menichini F: Antiproliferative effects of essential oils and their major constituents in human renal adenocarcinoma and amelanotic melanoma cells. Cell Prolif 41: 1002-1012, 2008.

10. Paik SY, Koh KH, Beak SM, Paek SH and Kim JA: The essential oils from Zanthoxylum schinifolium pericarp induce apoptosis of HepG2 human hepatoma cells through increased production of reactive oxygen species. Biol Pharm Bull 28: 802-807, 2005.

11. Gu Y, Ting Z, Qiu X, Zhang X, Gan X, Fang Y, Xu X and Xu R: Linalool preferentially induces robust apoptosis of various leukemia cells via upregulating p53 and cyclin-dependent kinase inhibitors. Toxicology 268: 19-24, 2010.

12. Goto T, Takahashi N, Hirai S and Kawada T: Various terpenoids derived from herbal and dietary plants function as PPAR modulators and regulate carbohydrate and lipid metabolism. PPAR Res 2010: 483958, 2010.

13. Castaigne S, Chomienne C, Daniel MT, Ballerini P, Berger R, Fenaux P and Degos L: All-trans retinoic acid as a differentiation therapy for acute promyelocytic leukemia. I. Clinical results. Blood 769: 1704-1709, 1990.

14. Mishima S, Inoh Y, Narita Y, Ohta S, Sakamoto T, Araki Y, Suzuki KM, Akao Y and Nozawa Y: Identification of caffeoylquinic acid derivatives from Brazilian propolis as constituents involved in induction of granulocytic differentiation of HL-60 cells. Bioorg Med Chem 13: 5814-5818, 2005.

15. Kuo HC, Kuo WH, Lee YJ, Wang CJ and Tseng TH: Enhancement of acid phenethyl ester on all-trans retinoic acidinduced differentiation in human leukemia HL-60 cells. Toxicol Appl Pharmacol 216: 80-88, 2006.

16. Breitman TR, Selonick SE and Collins SJ: Induction of differentiation of the human promyelocytic leukemia cell line (HL-60) by retinoic acid. Proc Natl Acad Sci USA 77: 2936-2940, 1980.

17. Moteki H, Hibasami H, Yamada Y, Katsuzaki H, Imai K and Komiya T: Specific induction of apoptosis by 1,8-cineole in two human leukemia cell lines, but not in a human stomach cancer cell line. Oncol Rep 9: 757-760, 2002.

18. Sokoloski JA, Hodnick WF, Mayne ST, Cinquina C, Kim CS and Sartorelli AC: Induction of the differentiation of HL-60 promyelocytic leukemia cells by vitamin $\mathrm{E}$ and other antioxidants in combination with low levels of vitamin D3: possible relationship to NF-kappaB. Leukemia 11: 1546-1553, 1997.

19. Linney E: Retinoic acid receptors transcription factors modulating gene regulation, development, and differentiation. Curr Top Dev Biol 27: 309-350, 1992.

20. Robertson KA, Emami B, Mueller L and Collins SJ: Multiple members of the retinoic acid receptor family are capable of mediating the granulocytic differentiation of HL-60 cells. Mol Cell Biol 12: 3743-3749, 1992.

21. Fenaux P, Castaigne S, Chomienne C, Dombret H and Degos L: All trans retinoic acid treatment for patients with acute promyelocytic leukemia. Leukemia 6: 64-66, 1992.

22. Cornic $M$ and Chomienne $C$ : Induction of retinoid resistance by all-trans retinoic acid in acute promyelocytic leukemia after remission. Leuk Lymphoma 18: 249-257, 1995.

23. Jagdeo J, Campbell R, Long T, Muglia J, Telang G and Robinson-Bostom L: Sweet's syndrome-like neutrophilic lobular panniculitis associated with all-trans-retinoic acid chemotherapy in a patient with acute promyelocytic leukemia. J Am Acad Dermatol 56: 690-693, 2007. 